\title{
SEISMOLOGICAL EVIDENCE INDICATING RUPTURE ALONG AN EASTWARD DIPPING FAULT PLANE FOR THE 1964 NIIGATA, JAPAN EARTHQUAKE
}

\author{
Jim Mori and Thomas BOYD \\ Lamont-Doherty Geological Observatory and Department of Geological Sciences of \\ Columbia University, Palisades, New York 10964, U.S.A.
}

(Received November 14, 1984; Revised March 19, 1985)

\begin{abstract}
The Niigata earthquake of June $16,1964\left(M_{\mathrm{s}}=7.5\right)$ is studied using a bodywave inversion technique on teleseismic $\mathbf{P}$ waveforms of the mainshock and a joint hypocenter determination of 27 of the largest $\left(M_{\mathrm{JMA}} \geqq 4.0\right)$ regionally recorded aftershocks. The mainshock is interpreted as being composed of two subevents with moments of $2.1 \times 10^{26}$ dyn-cm and $2.0 \times 10^{27}$ dyn-cm. The focal mechanism indicates that faulting could have occurred on either a plane dipping toward the west or a plane dipping toward the east. The initial subevent is located at a depth of 8 to $13 \mathrm{~km}$, while the centroid of the second subevent is located $27 \mathrm{~km}$ southwest of the first and at a depth of $3 \mathrm{~km}$. The relocated aftershocks all appear to have depths of less than $15 \mathrm{~km}$ which is consistent with the depths obtained for the mainshock. They appear to define a trend dipping shallowly toward the east which is consistent with the relative locations of the two subevents comprising the mainshock. We conclude, therefore, that a fault plane dipping toward the east is more consistent with the relative locations of the two subevents and the relocations of the aftershocks.
\end{abstract}

\section{Introduction}

Recently there has been interest in the earthquakes along the eastern margin of the Japan Sea because of the suggestions that the boundary between the Eurasian and North American plates passes through this region (FUKAO and FURUMOTO, 1975; NAKamura, 1983; Seno and EguCHI, 1983). The Niigata earthquake of June $16,1964\left(M_{\mathrm{S}}=7.5\right)$ was one of the larger events to have occurred in this region during the last twenty years (Fig. 1). This earthquake was located fairly close to shore where seismic stations were operating and crustal deformation measurements were made, yet, the orientation of the fault plane has not been clearly determined. The focal mechanism has been well constrained to be a thrust solution striking approximately north, with one nodal plane dipping steeply toward the west and the other dipping at a low angle toward the east (HIRASAWA, 1965; ABE, 1975). An accurate knowledge of the depth and the plane of rupture for the 1964 Niigata earthquake may be critical when evaluating the tectonic regime of the eastern Japan Sea.

ABE (1975) showed that the subsidence measured from leveling data on the 


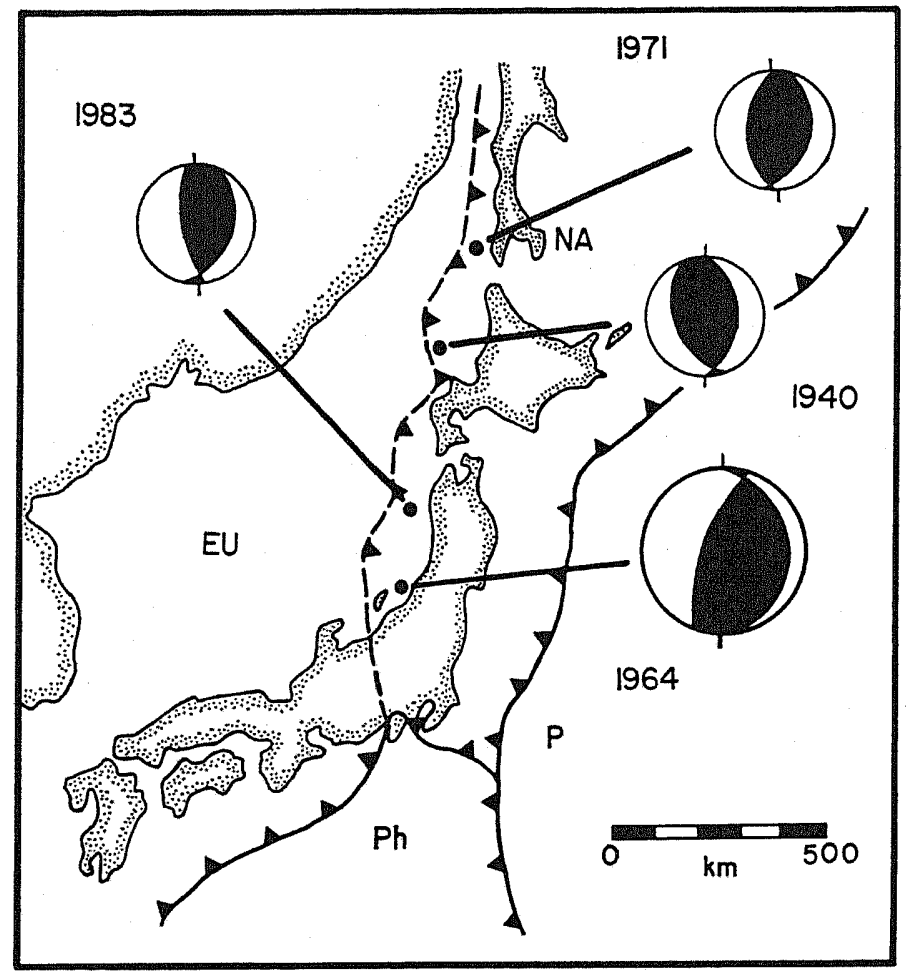

Fig. 1. Tectonic setting of the 1964 Niigata earthquake. Barbed solid lines are known subduction zones, while the barbed dashed line is the hypothesized boundary between the North American and Eurasian plates (NAKAmuRA, 1983; Seno and EGUCHI, 1983). Plates are identified as; EU, Eurasian; NA, North American; $\mathrm{P}$, Pacific; and $\mathrm{Ph}$, Philippine. Included on this figure are the source mechanisms for the 1964 event (ABE, 1975), the 1983 Akita-Oki event (SHIMAZAKI and MoRI, 1983), and the 1971 Sakhalin and 1940 Shakotan events (FukAo and FurUmoto, 1975).

western shore of Honshu and one tilt measurement could be modeled by assuming the steeply westward dipping plane was the fault plane. This conclusion is supported by fault scarps presummed to be Holocene in age, near the aftershock region which have been interpreted as indicating westward dipping fault planes (TAMAKI, 1984). SATAKE and ABE (1983) showed, however, that with the inclusion of seafloor deformation data from within the aftershock zone, that a lowangle eastward dipping plane is more appropriate. An aftershock study done following the earthquake did not show any clear trend that could be identified as a fault plane (KAYANO, 1968). Recently, this data has been re-examined by HAMADA (1983) who has interpreted the results as indicating rupture along a steeply westward dipping plane. Teleseismic $P$ waves have been examined, first by Hirasawa (1965) and later by Sudo (1972). Both identified a subevent ap- 
proximately $5 \mathrm{~s}$ after the initial first motion. The location of the subevent relative to the initial hypocenter indicates rupture upward and toward the east, this result, however, requires an epicentral resolution of $3 \mathrm{~km}$.

\section{Inversion of Teleseismic $P$ Waves}

Ten long-period $\mathrm{P}$ waves recorded at teleseismic distances on World Wide Standard Seismic Network (WWSSN) instruments were modeled using the inversion method of NABELEK (1984). Briefly, this procedure involves parameterizing the synthetic seismograms $s(t)$ as follows,

$$
s(t)=M_{n} \sum_{k=1}^{n} \sum_{i=1}^{3} w_{k} H_{i}\left(t-\tau_{k}-\eta_{i} d\right) \tau_{i}
$$

where

$$
H_{i}(t)=h_{i}(t)^{*} T_{\Delta \tau}(t)^{*} M(t)^{*} C^{\mathrm{R}}(t)^{*} R_{t}(t)
$$

and: $M_{n}$-moment tensor norm; $w_{k}$-weight of source time function element $k$; $t$-time; $\tau_{k}$-time increment between elements of the source time function; $\eta_{i}$ average vertical slowness near source ( 0 for the direct P); $d$-depth; $\tau_{i}$-normalized source radiation pattern; $k=1, \ldots, n$ index for each source time function element; $i-1$ for the direct $\mathrm{P}, 2$ for $\mathrm{pP}, 3$ for $\mathrm{sP} ; H_{i}(r)$-elementary seismogram which is a convolution of; $h_{i}(t)$-response of the crust near source; $T_{A t}(t)$-normalized source time function element; $M(t)$-mantle response (attenuation); $C^{\mathrm{R}}(t)$ receiver crustal response; $R_{t}(t)$-receiver (instrument) response.

Any of the variables representing the moment $\left(M_{n}\right)$, the source time function $\left(w_{1}, w_{2}, \ldots, w_{n}\right)$, the depth $(d)$ or the focal mechanism $\left(r_{i}\right)$ can be solved for using an iterative maximum likelihood inverse in which the sum of the squares of the errors between the data and synthetics is minimized. A priori estimates of all the unknowns are necessary and iterative improvements of the unknowns are calculated until the solution converges. For multiple events the seismogram $S(t)$ is a sum of seismograms that are time-shifted by $\Delta \tau_{i}$ which is the delay of the subevent $i$ and by the directivity function $\zeta_{i}=p \rho_{i} \cos \left(\varphi-\phi_{i}\right)$ where $p$ is the ray parameter, $\rho_{i}$ is the horizontal distance to the subevent, $\varphi$ is the station azimuth and $\psi_{i}$ is the azimuth to the subevent

$$
S(t)=s_{1}(t)+s_{2}\left(t-\Delta \tau_{2}+\zeta_{2}\right)+s_{3}\left(t-\Delta \tau_{3}+\zeta_{3}\right)+\cdots .
$$

The inversion will then solve for $\Delta \tau_{i}, \rho_{i}$, and $\phi_{i}$ and give the time delays and relative locations of the subevents. For more details see NABELEK (1984).

Examination of the waveforms suggests that the Niigata earthquake is not a single simple event, but consists of at least two subevents, with the second subevent arriving about $10 \mathrm{~s}$ after the first motion on seismograms recorded at many teleseismic distances. The small initial arrival and larger arrival 4 to $6 \mathrm{~s}$ later which were identified as separate sources by HIRASAWA (1965) and Sudo (1972) 
were treated together as the first subevent in this study, since there does not appear to be a large distance between their relative locations. Under the assumption that the $\mathbf{P}$ waveform is primarily composed of two subevents the inversion solved for the focal mechanism, depth, moment and source time function of the two subevents and the relative location of the second subevent with respect to the first one. The crustal structure used by the inversion procedure was a $6.0 \mathrm{~km} / \mathrm{s}$ halfspace underlying a $1.0 \mathrm{~km}$ thick water layer at the source, and a $6.0 \mathrm{~km} / \mathrm{s}$ halfspace at each receiver.

In practice the procedure involved holding some of the unknowns fixed and solving for others to first find reasonable starting values. We initially held the depth and the focal mechanism of the first subevent fixed to what we believed were reasonable starting estimates (e.g., the focal mechanism determined by $\mathrm{ABE}$ (1975), and a depth of $\sim 10 \mathrm{~km}$ ) while inverting for the source parameters of the second subevent and the moment of the first subevent. Holding the estimates of the second subevent fixed, we then inverted for the source mechanism and depth of the first subevent. Once these starting values were determined the inversion was allowed to solve for all the variables simultaneously. Using several different starting values it was found that the depth and focal mechanism of the larger second subevent were quite stable. However, the focal mechanism and depth of the first subevent varied considerably more. This is because the second subevent masks the latter part of the waveform of the first subevent so that it is difficult to accurately resolve the $\mathrm{pP}$ and $\mathrm{sP}$ contributions of the first subevent.

The results of the inversion are given in Table 1 and the corresponding synthetic seismograms are shown in Fig. 2. The total seismic moment determined from the inversion appears to be significantly less than that determined from previous surface wave studies (Table 2). This difference may indicate that only a portion of the total energy release is observed in the moment estimate based on long-period body waves. The focal mechanism of the Niigata earthquake has been studied extensively using a wide variety of data (e.g., Table 2). ABE (1975) performed the most extensive study of the source mechanism and found that two

Table 1. Inversion Results.

\begin{tabular}{lcccc}
\hline & \multicolumn{2}{c}{ Mainshock $(06 / 16 / 64)$} & & Aftershock \\
\cline { 2 - 3 } & Subevent 1 & Subevent 2 & & $(07 / 12 / 64)$ \\
\hline Moment $($ dyn-cm) & $2.1 \times 10^{26}$ & $2.0 \times 10^{27}$ & & $4.1 \times 10^{24}$ \\
Strike & 256. & 210. & 191. \\
Dip & 36. & 50. & 71. \\
Rake & 136. & 116. & 72. \\
Depth $(\mathrm{km})$ & 10. & 3. & 8. \\
Azimuth & & 244. & \\
Distance* $(\mathrm{km})$ & & 27. & \\
\hline
\end{tabular}

* Relative location of second subevent with respect to the first, azimuth is given in degrees from north and distance in $\mathrm{km}$. 


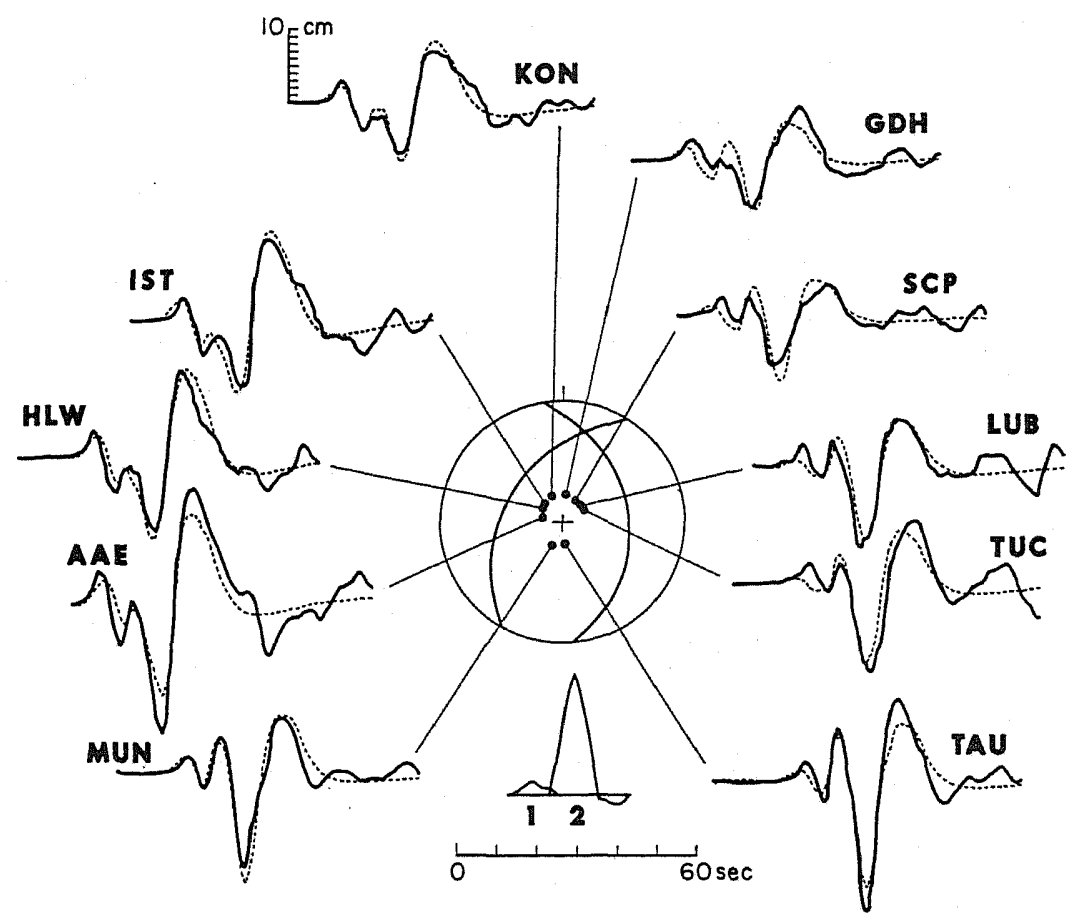

Fig. 2. Synthetic seismograms obtained from the inversion of $\mathbf{P}$-waves from the mainshock (Observed, solid lines and calculated, dashed lines). All seismograms are normalized to a magnification of 3,000 and a distance of $50^{\circ}$. Below is shown the source-time functions for both the first and second subevents. Included in the center of the figure is the lower hemisphere projection of the focal mechanism determined for the second subevent.

models were each consistent with several of the observations. He concluded that the differences between these models may be due to initial rupture having started on a slightly different fault plane than the main rupture. Our fault plane solution for the second subevent is intermediate between those of ABE (1975). Also, at teleseismic distances, the use of P-waveform data does not provide constraints on the strike of $45^{\circ}$ dipping nodal planes (NABELEK, 1984). In light of these considerations, we feel that the solution presented here for the second subevent is not significantly different from those previously proposed. The focal mechanism of the first subevent, however, is significantly different, but there is a large uncertainty in its determination as discussed above. These uncertainties are relatively unimportant in this study since our intent is not to introduce new source mechanisms for the Niigata earthquake, but rather to examine the spacetime variation of the energy release.

The location of the second subevent relative to the first one was at a distance of $27.0 \mathrm{~km}$ and an azimuth of $245^{\circ}$ (Fig. 3). The time delay between the 
Table 2. Niigata 1964 Earthquake-Data sets and results.

\begin{tabular}{|c|c|c|c|c|}
\hline Reference & $\begin{array}{c}\text { Focal Mechanism } \\
\text { (lower) }\end{array}$ & $\begin{array}{c}\text { Dip of Fault } \\
\text { Plane }\end{array}$ & $\begin{array}{c}\begin{array}{c}\text { Moment } \\
\text { (dyne-cm) }\end{array} \\
\end{array}$ & Data \\
\hline Hirasawa (1965) & & & & Teleseismic $\mathrm{P} \& \mathrm{~S}$ \\
\hline Aki (1966) & & $\begin{array}{l}\text { Steeply to } \\
\text { the west }\end{array}$ & $3.0 \times 10^{27}$ & $\begin{array}{l}\text { Teleseismic \& } \\
\text { regional P } \\
\text { Teleseismic surface } \\
\text { waves }\end{array}$ \\
\hline Sudo (1972) & & $\begin{array}{l}\text { Steeply to } \\
\text { the west }\end{array}$ & & Teleseismic $P$ \\
\hline Abe (1975) & & $\begin{array}{l}\text { Steeply to } \\
\text { the west }\end{array}$ & $3.2 \times 10^{27}$ & $\begin{array}{l}\text { Teleseismic \& } \\
\text { regional P \& S } \\
\text { Teleseismic surface } \\
\text { waves } \\
\text { Levelling } \\
\text { Tilt measurement }\end{array}$ \\
\hline Hamada (1883) & & $\begin{array}{l}\text { Steeply to } \\
\text { the west }\end{array}$ & & Aftershocks \\
\hline $\begin{array}{l}\text { Satake \& } \\
\text { Abe (1983) }\end{array}$ & & $\begin{array}{l}\text { Shallowly to } \\
\text { the east }\end{array}$ & & $\begin{array}{l}\text { Levelling } \\
\text { Tilt measurement } \\
\text { Seafloor } \\
\text { deformation }\end{array}$ \\
\hline Present Study & & $\begin{array}{l}\text { Shallowly to } \\
\text { the east }\end{array}$ & $2.2 \times 10^{27}$ & $\begin{array}{l}\text { Teleseismic P } \\
\text { Aftershocks }\end{array}$ \\
\hline
\end{tabular}

two subevents indicates a rupture velocity of between 2.7 to $2.8 \mathrm{~km} / \mathrm{s}$, depending on the assumed depth of the first subevent. The accuracy of choosing the onset of each subevent is about $\pm 0.5 \mathrm{~s}$. The epicentral location of the first subevent was determined using the regional network and applying the station adjustments determined from the aftershock study. A reading error of $0.5 \mathrm{~s}$ implies that the epicentral accuracy is about $\pm 3.0 \mathrm{~km}$. The epicentral location of the second subevent was based on teleseismic arrivals. A $0.5 \mathrm{~s}$ reading error in this case implies an epicentral accuracy of about $\pm 10.0 \mathrm{~km}$. The depth errors for each subevent were determined by choosing different starting depths and observing the range of convergence, which was about $\pm 10.0 \mathrm{~km}$ for the first subevent, and $\pm 2.0 \mathrm{~km}$ for the second. There is not a reliable, independent estimate of the depth of the initial hypocenter based on regionally recorded data because of the lack of 
good S wave arrivals. Even though the depth control on the first subevent is not very good, the fact that the second subevent is quite shallow and located toward the west relative to the first strongly suggests that the fault plane dips toward the east, assuming these two subevents lie on the same fault plane.

The dashed and dotted lines in the cross section of Fig. 3 show the orientations of the nodal planes for the first-motion focal mechanism of ABE (1975) and the inversion results for the second subevent, respectively. The relative locations of the subevents fits the eastward dipping plane of the first-motion focal mechanism better than the eastward dipping plane of the inversion. Given that the focal mechanism shown in Fig. 3 is that of the second subevent, it represents the mechanism associated with moment release about $10 \mathrm{~s}$ after the initial motion. The misfit of the relative locations of the subevents with respect to the fault plane predicted by the inversion may indicate a steepening of the dip of the fault plane as the rupture progressed to the west. This kind of listric thrusting or
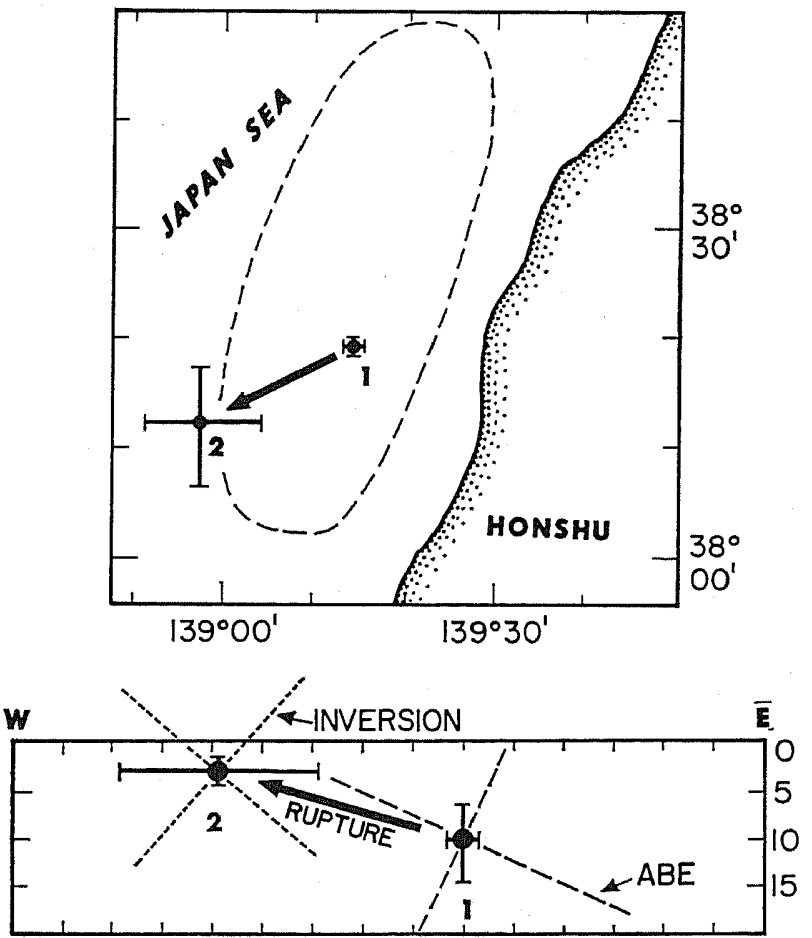

Fig. 3. Relative position of the two subevents forming the mainshock. Upper portion of the figure indicates the epicentral position of the two subevents. The dashed line is the tsunami source area inferred from (IIDA, 1968). Lower portion of the figure is an east/west cross section of the two events. The dashed lines represent the nodal planes as determined by ABE (1975; Model II), while the dotted lines are those determined by the inversion. Vertical and horizontal divisions on the east/ west cross section are every $5 \mathrm{~km}$. 
high-angle faulting within large shallowly dipping thrust events has been suggested previously in Japan by various authors (e.g., FuKAO, 1979; KATO, 1983). Alternatively, the misfit may indicate that the two subevents are on different fault planes. If the two subevents are not located on the same fault, then their relative locations do not preclude a westward dipping fault plane. For example, it is possible that the two subevents could have occurred on two parallel faults dipping steeply to the west.

\section{Relocations of Aftershocks}

Aftershocks with magnitudes determined by the Japanese Meteorological Agency (JMA) to be greater or equal to 4.0 were relocated using a Joint Hypocenter Determination (JHD) program (DEWEY, 1971). JHD simultaneously inverts arrival time information from a group of spatially related earthquakes to determine both their hypocentral parameters and station adjustments. To prevent instabilities in the inversion, the present procedure requires that the location of a calibration (master) event be known a priori and that all of the earthquakes occur within the same source region.

Arrival time data used in this study consisted of both $\mathrm{P}$ and $\mathrm{S}$ readings from regional JMA stations. Due to our incomplete knowledge of the velocity struc-

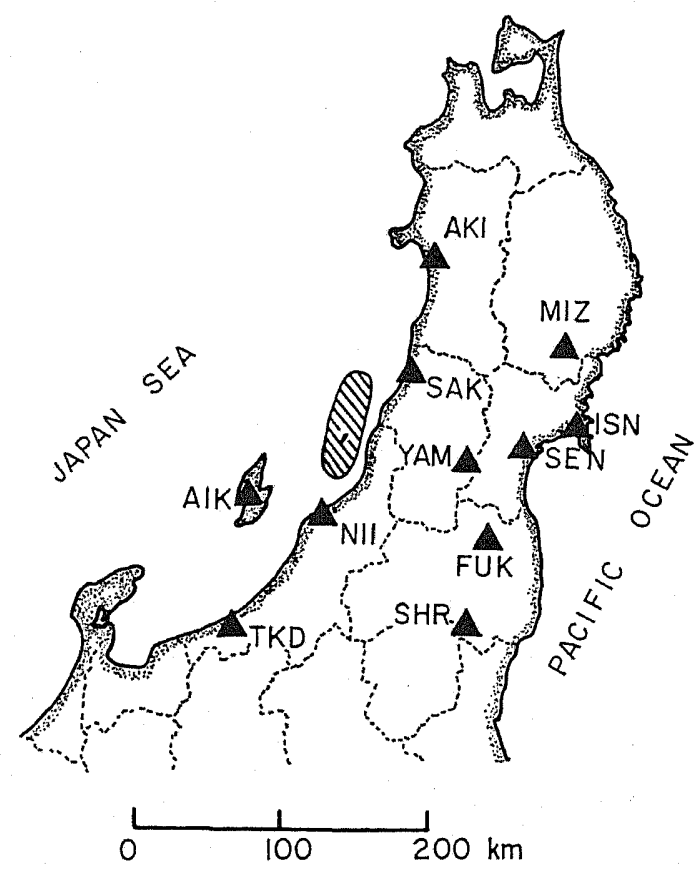

Fig. 4. Location of the seismic stations (triangles) used to relocate the aftershocks. The tsunami source area is indicated by the hatched area. 
ture, only stations closer than two degrees of the aftershock area were used in the inversion (Fig. 4). The distribution of stations used for the relocation scheme is far from optimal, with only one station to the southwest and no stations to the west. Given that the nearest stations are at least $20 \mathrm{~km}$ from the aftershock zone, uncertainties in the relative depths of the relocated events will be quite large. To improve the depth resolution, we required that all of the relocated events have at least two consistent $S$ arrivals at stations within $100 \mathrm{~km}$. Using this screening criteria we selected 27 of the larger aftershocks. The velocity model used for all the earthquake relocations was that of ICHIKAWA and MocHIZUKI (1971).

The largest aftershock $\left(M_{\text {JMA }}=6.0\right)$ which occurred on July 12,1964 was used as the master event. In order to obtain a good depth for the master, the teleseismic $\mathrm{P}$ waves were modeled using the same inversion technique described above for the mainshock (Fig. 5 and Table 1). The focal mechanism determined by the inversion procedure is very close to that obtained by HIRASAWA (1965) using $P$ first motions and S-wave polarizations. The depth of this aftershock was determined to be 6 to $8 \mathrm{~km}$ depending on whether all the stations were weighted equally or the North American stations were down-weighted for a more evenly weighted azimuthal coverage. A depth of $7 \mathrm{~km}$ was used for the master in the JHD relocations. The epicentral location of the master was then determined using regional arrival time data while holding the depth fixed at $7 \mathrm{~km}$.

The aftershock region is quite large $(80 \times 40 \mathrm{~km})$. To account for varying travel path effects from different sections of the aftershock area, only events lying within a small region were simultaneously inverted (within $\sim 25 \mathrm{~km}$ of the master event). The first 15 events were relocated using the July 12 aftershock as the

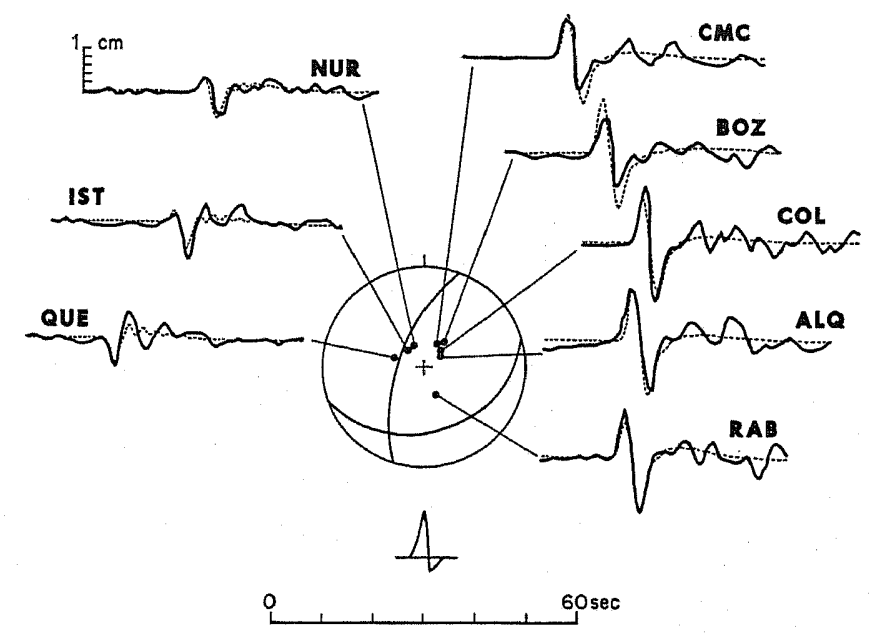

Fig. 5. Synthetic seismograms obtained from the inversion of P-wave data for the aftershock of July 12, 1964 (All symbols as in Fig. 2). 

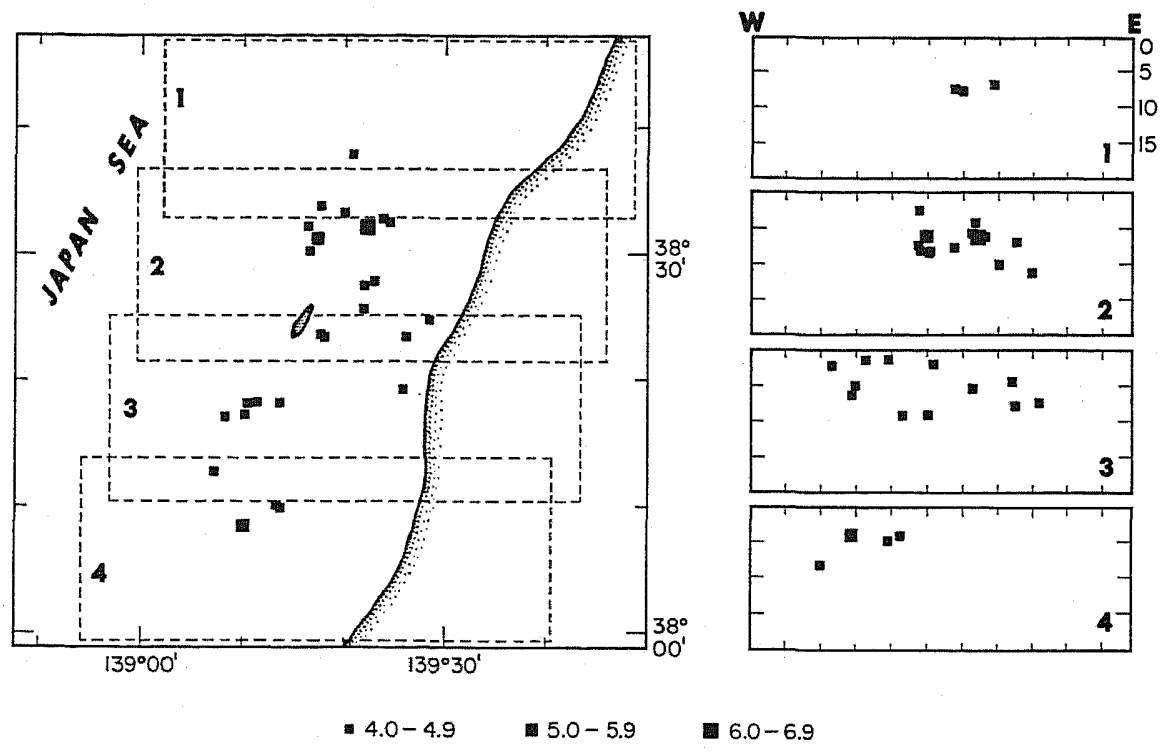

Fig. 6. Relocations of the 27 aftershocks. The left portion of the figure shows the epicentral relocations (squares) of the aftershocks and the regions in which the events were simultaneously relocated using JHD. The largest square is the location of the initial master event. The right side of the figure displays east/west cross sections through the four regions. Vertical and horizontal divisions on the east/west cross sections are every $5 \mathrm{~km}$.

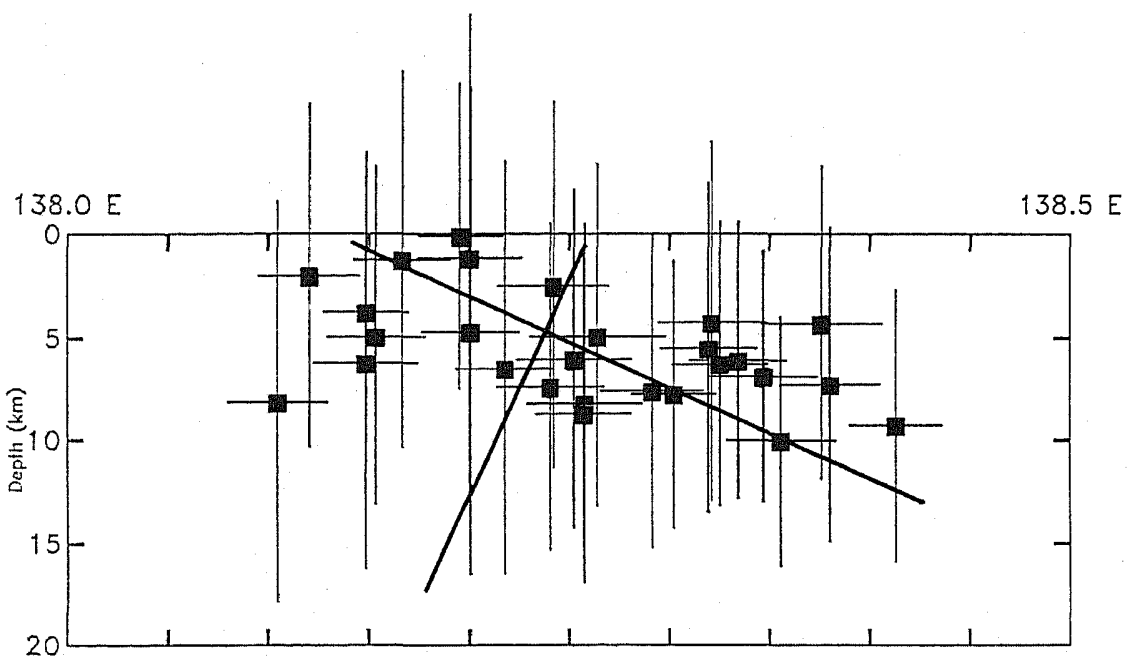

Fig. 7. Composite east/west cross section of all the relocated events shown in Fig. 6. Error bars are major and minor axes of the $70 \%$ confidence ellipses for the longitude and depth. The solid intersecting lines represent possible fault planes for the mainshock and intersect each other at the epicentral location of subevent 1 . All depths are given in $\mathrm{km}$. Vertical and horizontal divisions on are every $5 \mathrm{~km}$. 
master event (Fig. 6, box 2). Next, the 13 events of box 3 were relocated with a master event from the region where boxes 2 and 3 overlap. In a similar way the events in the other boxes were relocated using as a master, an event from the region where the two boxes overlap. The corresponding cross sections for each box are shown on the right of Fig. 6 . Only boxes 2 and 3 have a reasonable number of events, and both of these sections show location distributions that appear to be more consistent with a plane that dips shallowly toward the east than steeply toward the west.

Figure 7 shows a composite cross section of all four boxes with the estimated $70 \%$ joint confidence limits for the longitude and depth of each event. The errors in horizontal distance are generally quite small, $\sim 2 \mathrm{~km}$ in latitude and $\sim 3 \mathrm{~km}$ in longitude. The errors in depth are considerably larger, 5 to $10 \mathrm{~km}$, due to the large distances to the closest station. Even with these large uncertainties, the aftershock distribution is indicative of a plane shallowly dipping toward the east, and it is difficult to group the aftershock locations in any way about the plane dipping steeply toward the west.

Our aftershock distribution looks very different from that of HAMADA (1983), even though the same data and velocity structure were used. One reason is that we relocated events with respect to a master event which we believed to be well constrained at a depth of $7 \mathrm{~km}$. The shallow depth of the master brought the whole distribution of aftershocks to shallow depths. The depth distribution of the aftershocks is not unreasonable and is consistent with that at the mainshock subevents determined from P-wave modeling. Another difference in the way the aftershocks were relocated is that we were more selective in the events that we felt were well located. Perhaps, we were too selective and a larger distribution of events is necessary to show the shape of the aftershock distribution. When we included more events, however, the distribution of the aftershocks becomes much more diffuse. The scatter present in the aftershock locations is probably due to poor depth control, compounded by a lack of reliable $S$ readings, although some of the scatter may suggest that not all of the aftershocks occurred on the rupture plane of the mainshock.

\section{Discussion}

The inversion results (Fig. 3) and the aftershock distribution (Fig. 7) suggest that the eastward dipping plane is the fault plane. The two results are combined in Fig. 8 and plotted at different azimuths to see if the cross sections change significantly. A, B, C, and D represent cross sections at azimuths of $80,90,100$, and $110^{\circ}$, respectively. In map view the aftershock distribution appears to strike 10 to $20^{\circ}$ east of north, although this is also the direction parallel to the coast, and thus could be a systematic bias due to the station distribution. The focal mechanism of ABE (1975) and this study show that the eastward dipping plane strikes more northerly. However, since the cross-sections do not differ sig- 

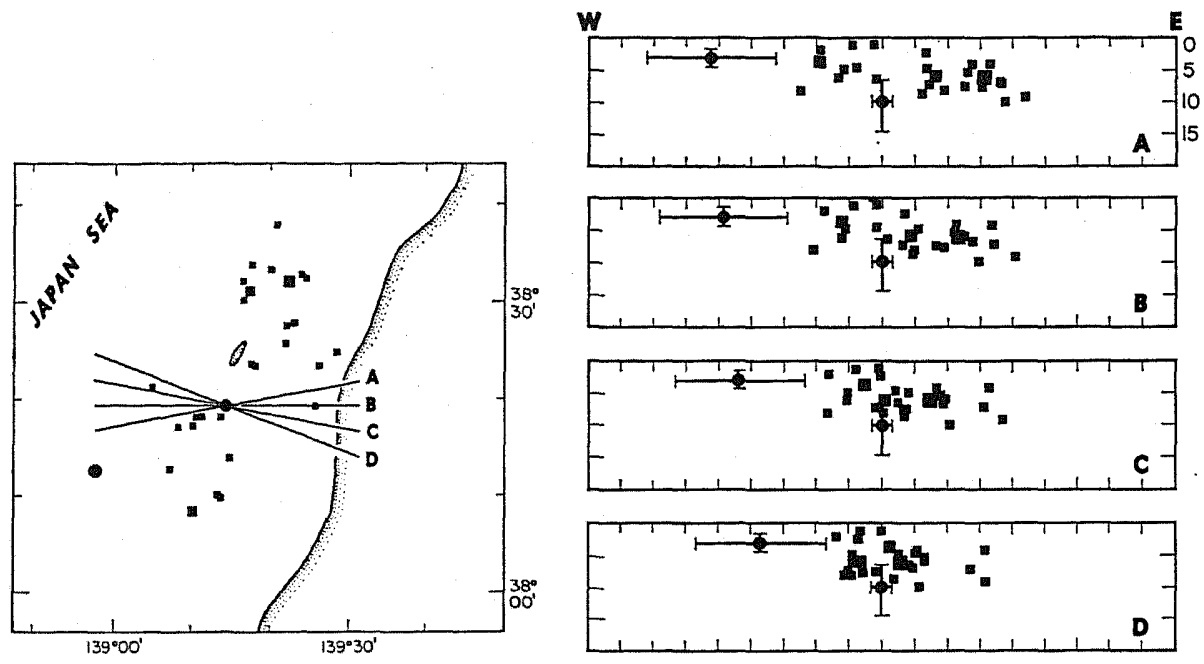

Fig. 8. Combined results of the bodywave inversion and the aftershock relocation. The left portion of the figure indicates the orientation of each cross section shown on the right portion of the figure. Closed circles are the hypocentral locations of the two subevents. All other symbols and scales are as in Fig. 6.

nificantly when the errors in the depth estimates are considered, it is not possible to resolve the strike of the fault plane.

There is some discrepancy in the locations of the subevents with respect to the aftershocks. The subevents are located slightly westward of the aftershocks. However, these differences are within the location errors and as such are not significant.

An interesting feature of this earthquake is its shallow depth. The depth of the second subevent appears to be well constrained at $3 \mathrm{~km}$. Given that this is the centroid location of a subevent with a relatively large moment, one would expect the rupture to have broken the surface, especially with the steeper dip angle of the nodal planes of the second subevent. However, there is not any other strong evidence which indicates a large surface break for this earthquake.

If this earthquake is an event within a young subduction zone, its shallow depth requires that it be located relatively close to the trench axis (Fig. 1). The plate boundary as suggested by NAKAMURA (1983) is too far west to accommodate this earthquake, so either the plate boundary must be moved eastward or this event represents shallow angle thrusting located slightly off the main interface. Since this is presumably a young tectonic feature, another possibility is that the main thrust interface may not have developed yet and there could be shallowangle thrusting along various subparallel faults within a broader area of compressional deformation. 


\section{Conclusions}

Both the locations of the subevents determined from an inversion of the teleseismic $\mathrm{P}$ waves and the distribution of aftershocks as relocated using the JHD method, show trends that are more consistent with a fault plane that dips toward the east rather than a plane that dips toward the west. The uncertainties in both results, however, are such that a precise determination of the dip angle cannot be made. This paper along with that of SATAKE and ABE (1983) reflects a change from previous interpretations of the orientation of the fault plane (see Table 2). This change is reasonable in light of the 1983 Japan Sea earthquake $\left(M_{\mathrm{S}}=7.7\right)$ which occurred $200 \mathrm{~km}$ to the north, presumably on the same inferred plate boundary, which was shown to rupture along a plane dipping shallowly toward the east (UMINo et al., 1983; SATo et al., 1984).

We would like to thank K. Nakamura for initially exposing us to this problem, J. Nabelek for the use of his program, and G. Suarez for an introduction to its use. Critical reviews and helpful comments were provided by K. Jacob, G. Suarez, and two reviewers.

\section{REFERENCES}

ABE, K., Re-examination of the fault model for the Niigata earthquake of 1964, J. Phys. Earth, 23, 349-366, 1975.

AKI, K., Generation and propagation of $\mathrm{G}$ waves from the Niigata earthquake of June 16, 1964. Part 2. Estimation of earthquake moment, released energy and stress-strain drop from the G wave spectrum, Bull. Earthq. Res. Inst. Univ. Tokyo, 44, 73-88, 1966.

DEWEY, J., Seismicity studies with the method of joint hypocenter determination, Ph. D. Dissertation, Univ. of California, Berkeley, 116 pp., 1971.

FuKAO, Y., Tsunami earthquakes and subduction processes near deep-sea trenches, J. Geophys. Res., 84, 2303-2314, 1979.

FuKAo, Y. and M. FURUmoto, Mechanism of large earthquake along the eastern margin of the Japan Sea, Tectonophysics, 26, 247-266, 1975.

HAMADA, N., Re-examination of aftershock distribution of the Niigata earthquake in 1964, Zisin, 36, 663-667, 1983.

HiRASAWA, T., Source mechanism of the Niigata earthquake of June 16, 1964, as derived from body wave, J. Phys. Earth, 13, 35-36, 1965.

ICHIKAWA, M. and E. MochIzUKI, Travel time tables for local earthquakes in and near Japan, Pap. Meteorol. Geophys., 22, 229-290, 1971 (in Japanese).

IIDA, K., Niigata tsunami of June 16, 1964, in General Report on the Niigata Earthquake of 1964 , ed. H. Kawasumi, pp. 97-177, Tokyo Electrical Engineering College Press, 1968.

KATO, T., High angle reverse faulting associated with the 1946 Nankaido earthquake, Tectonophysics, 96, 31-44, 1983.

KAYANO, I., Determination of origin times, epicenters and focal depths of aftershocks of the Niigata earthquake of June 16,1964: A preliminary report of the cooperative study of aftershocks of the Niigata earthquake, Bull. Earthq. Res. Inst., Univ. Tokyo, 46, 223-269, 1968.

NABELEK, J., Determination of earthquake source parameters from inversion of body waves, Ph. D. Dissertation, Mass. Inst. Tech., 360 pp., 1984.

NAKAMURA, K., Possible nascent trench along the eastern Japan Sea as the convergent boundary 
between Eurasian and North American plates, Bull. Earthq. Res. Inst., Univ. Tokyo, 58, 711722, 1983 (in Japanese).

SATAKE, K. and K. ABE, A fault model for the Niigata, Japan earthquake of June 16, 1964, $J$. Phys. Earth, 31, 217-223, 1983.

Sato, T., M. Kosuge, K. TanaKa, and H. Sato, Aftershock distribution of the 1983 Japan Sea Earthquake (Relocations from an inclined model), (abstract), Seismol. Soc. Jpn., 1984, No. 1, 37, 1984 (in Japanese).

Seno, T. and T. Eguchi, Seismotectonics of the Western Pacific, in Geodynamics of the Western Pacific Indonesian Region, ed. T. W. C. Hilde and S. Uyeda, Geodynamics, Ser. 11, pp. 546, Am. Geophys. Union and Geol. Soc. Am., 1983.

ShIMAZAKI, K., and MoRI, J., Focal mechanism of the May 26, 1983, Japan Sea earthquake, (abstract), Seismol. Soc. Jpn., 1983, No. 2, 15, 1983.

Sudo, K., Two distinct phases in the initial P-wave group of the Niigata earthquake of 1964 and of the Taiwan-Oki earthquake of 1966, J. Phys. Earth, 20, 111-125, 1972.

TAMAKI, K., Recent structure and tectonics of the eastern margin of the Japan Sea, The Earth Monthly, 6, 38-48, 1984 (in Japanese).

Umino, H., N. Matsuzawa, K. Ohara, H. Shimizu, A. Hasegawa, A. Takagi, M. Kosuge, K. TANAKA, T. SATo, and H. SATo, The 1983 Japan Sea Earthquake: Aftershock distribution, (abstract), Seismol. Soc. Jpn., 1983, No. 2, 4, 1984 (in Japanese). 